\title{
Stagnation-Point Flow toward a Vertical, Nonlinearly Stretching Sheet with Prescribed Surface Heat Flux
}

\author{
Sin Wei Wong, ${ }^{1}$ M. A. Omar Awang, ${ }^{1}$ and Anuar Ishak ${ }^{2}$ \\ ${ }^{1}$ Institute of Mathematical Sciences, University of Malaya, 50603 Kuala Lumpur, Malaysia \\ ${ }^{2}$ School of Mathematical Sciences, Faculty of Science and Technology, Universiti Kebangsaan Malaysia, \\ 43600 Bangi, Selangor, Malaysia \\ Correspondence should be addressed to Anuar Ishak; anuarishak@yahoo.com
}

Received 27 November 2012; Revised 31 January 2013; Accepted 31 January 2013

Academic Editor: Chein-Shan Liu

Copyright (C) 2013 Sin Wei Wong et al. This is an open access article distributed under the Creative Commons Attribution License, which permits unrestricted use, distribution, and reproduction in any medium, provided the original work is properly cited.

\begin{abstract}
An analysis is carried out to study the steady two-dimensional stagnation-point flow of an incompressible viscous fluid towards a stretching vertical sheet. It is assumed that the sheet is stretched nonlinearly, with prescribed surface heat flux. This problem is governed by three parameters: buoyancy, velocity exponent, and velocity ratio. Both assisting and opposing buoyant flows are considered. The governing partial differential equations are transformed into a system of ordinary differential equations and solved numerically by finite difference Keller-box method. The flow and heat transfer characteristics for different values of the governing parameters are analyzed and discussed. Dual solutions are found in the opposing buoyant flows, while the solution is unique for the assisting buoyant flows.
\end{abstract}

\section{Introduction}

The study of fluid flow and heat transfer due to a stretching surface has significant application in the industrial processes, for example, in polymer sheet extrusion from a die, drawing of plastic films, and manufacturing of glass fiber. The quality of the final product greatly depends on the heat transfer rate at the stretching surface as explained by Karwe and Jaluria $[1,2]$.

Different from the flow induced by a stretching horizontal plate (see Crane [3], Weidman and Magyari [4], and Weidman and Ali [5]), the effect of the buoyancy force could not be neglected for the vertical plate. There are several works that reported the flow and heat transfer characteristics that are brought about by the buoyancy force [6-11]. Ramachandran et al. [12] studied the effect of buoyancy force on the stagnation point flows past a vertically heated surface at rest and found that dual solutions exist in the buoyancy opposing flow region. In the present paper, in addition to the flow under the influence of buoyancy force as discussed by Ramachandran et al. [12], we discuss the consequent flow and heat transfer characteristics that are also brought about by the stretching sheet with power-law velocity variation. It is worth mentioning that the problems of the stagnation-point flow toward a stretching sheet have been considered by many authors [13-27], by considering various flow configurations as well as surface heating conditions.

\section{Problem Formulation}

Consider a mixed convection stagnation-point flow towards a vertical nonlinearly stretching sheet immersed in an incompressible viscous fluid, as shown in Figure 1. The Cartesian coordinates $(x, y)$ are taken such that the $x$-axis is measured along the sheet oriented in the upwards or downwards direction and the $y$-axis is normal to it. It is assumed that the wall stretching velocity is given by $U_{w}=a x^{m}$ and the far field inviscid velocity distribution in the neighborhood of the stagnation point $(0,0)$ is given by $U_{\infty}(x)=b x^{m}$, $V_{\infty}(y)=-b y^{m}$. The surface heat flux is in the form of $q_{w}(x)=c x^{(5 m-3) / 2}$ (see Merkin and Mahmood [28]), where $a, b, c$, and $m$ are constants. This $q_{w}(x)$ ensured that the 


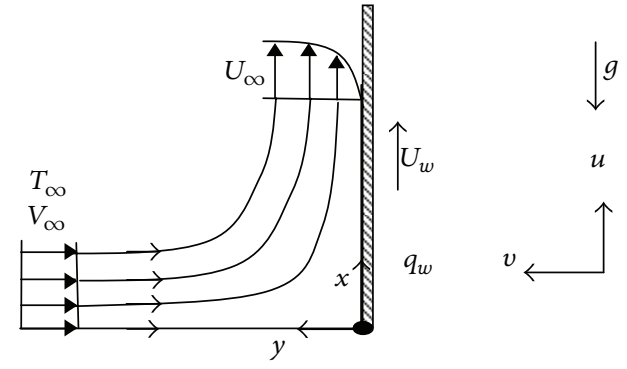

(a) Assisting flow $(\lambda>0)$

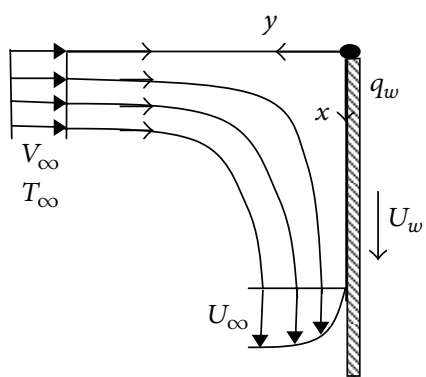

(b) Opposing flow $(\lambda<0)$

Figure 1: Physical model and coordinate system.

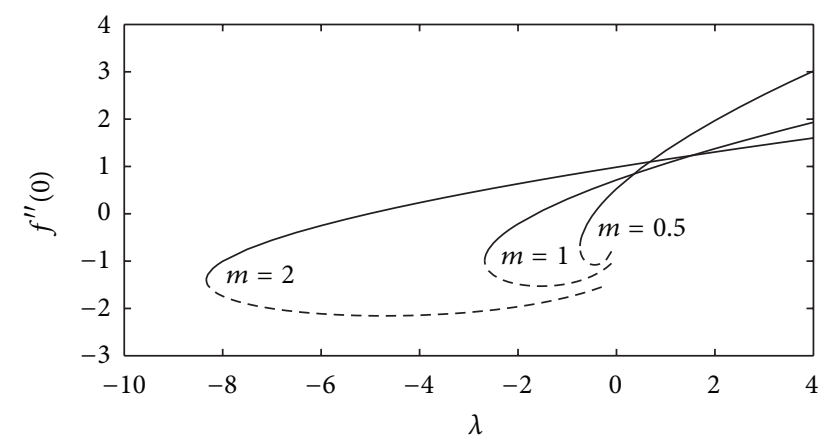

- Upper branch

- - - Lower branch

FIGURE 2: Variation of the skin friction coefficient $f^{\prime \prime}(0)$ with $\lambda$ for various values of $m$ when $\varepsilon=0.5$.

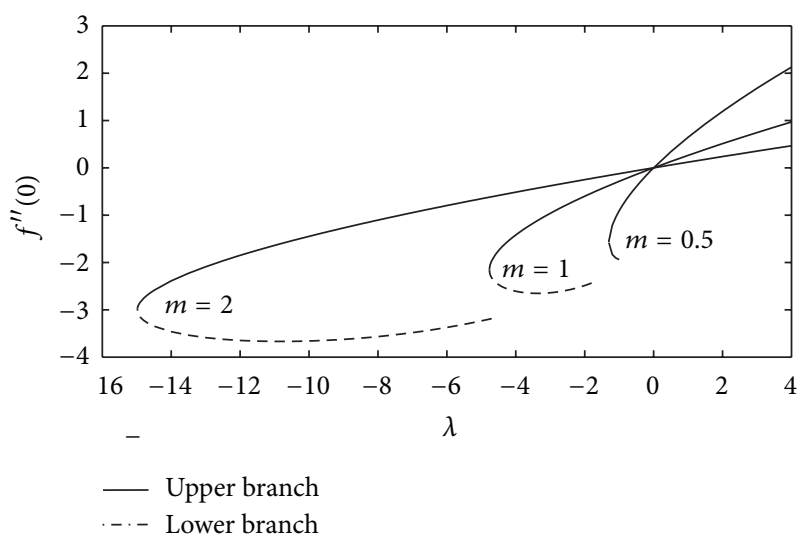

FIGURE 3: Variation of the skin friction coefficient $f^{\prime \prime}(0)$ with $\lambda$ for various values of $m$ when $\varepsilon=1$.

buoyancy parameter is independent of $x$. For the assisting flow, as shown in Figure 1(a), the $x$-axis points upwards in the same direction of the stretching surface such that the external flow and the stretching surface induce flow and heat transfer in the velocity and thermal boundary layers,

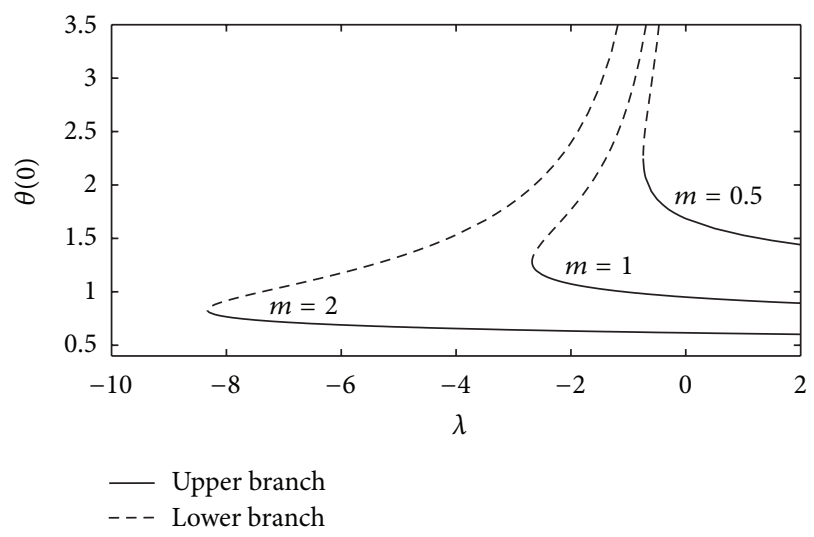

FIgURE 4: Variation of the wall temperature $\theta(0)$ with $\lambda$ for various values of $m$ when $\varepsilon=0.5$.

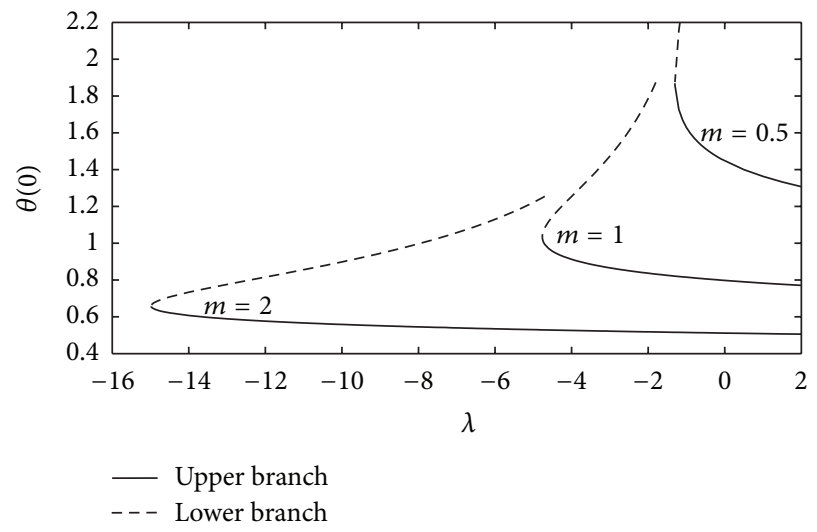

FIGURE 5: Variation of the wall temperature $\theta(0)$ with $\lambda$ for various values of $m$ when $\varepsilon=1$.

respectively. On the other hand, for the opposing flow, as shown in Figure 1(b), the $x$-axis points vertically downwards in the same direction of the stretching surface such that the external flow and the stretching surface also induce flow and heat transfer, respectively, in the velocity and thermal 


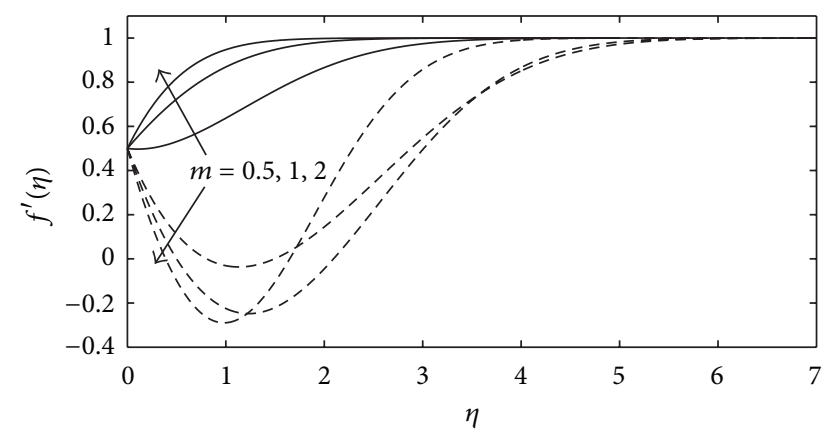

_- Upper branch

FIGURE 6: Velocity profile $f^{\prime}(\eta)$ for various values of $m$ when $\varepsilon=0.5$ and $\lambda=-0.5$.

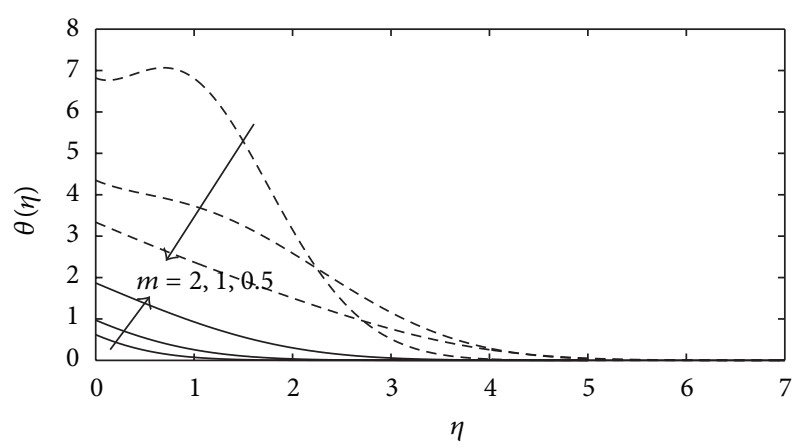

- Upper branch

-- - Lower branch

FigURE 7: Temperature profile $\theta(\eta)$ for various values of $m$ when $\varepsilon=0.5$ and $\lambda=-0.5$.

boundary layers. The steady boundary layer equations, with Boussinesq approximation, are

$$
\begin{gathered}
\frac{\partial u}{\partial x}+\frac{\partial v}{\partial y}=0 \\
u \frac{\partial u}{\partial x}+v \frac{\partial u}{\partial y}=U_{\infty} \frac{d U_{\infty}}{d x}+v \frac{\partial^{2} u}{\partial y^{2}}+g \beta\left(T-T_{\infty}\right) \\
u \frac{\partial T}{\partial x}+v \frac{\partial T}{\partial y}=\alpha \frac{\partial^{2} T}{\partial y^{2}}
\end{gathered}
$$

subject to the boundary conditions

$$
\begin{aligned}
& u=U_{w}(x), \\
& v=0, \\
& \frac{\partial T}{\partial y}=-\frac{q_{w}}{k} \quad \text { at } y=0, \\
& u \longrightarrow U_{\infty}(x), \quad T \longrightarrow T_{\infty} \text { as } y \longrightarrow \infty,
\end{aligned}
$$

where $u$ and $v$ are the velocity components along the $x$ - and $y$-axes, respectively, $g$ is the acceleration due to gravity, $\alpha$ is

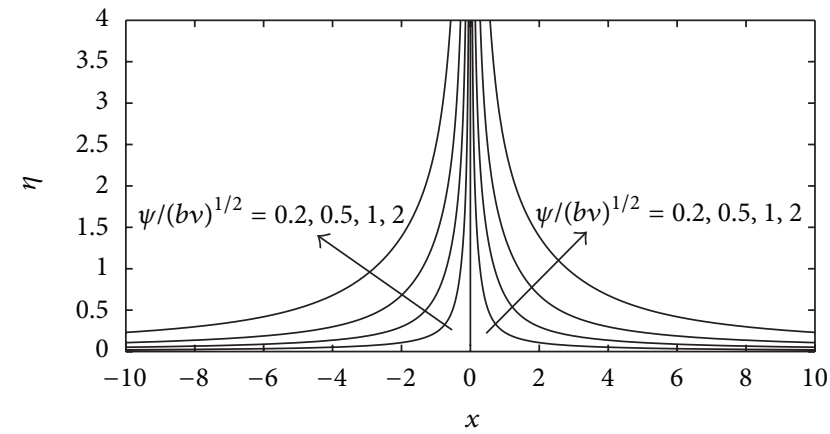

FIgURE 8: Streamlines for the upper branch solutions when $m=1, \varepsilon=1$, and $\lambda=-2$.

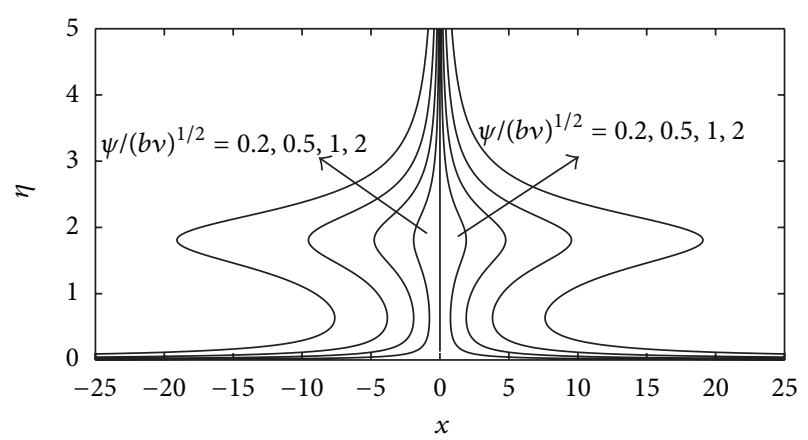

FIGURE 9: Streamlines for the lower branch solutions when $m=1, \varepsilon=1$, and $\lambda=-2$.

the thermal diffusivity of the fluid, $v$ is the kinematic viscosity, $\beta$ is the coefficient of thermal expansion, $\rho$ is the fluid density, and $T_{\infty}$ is the far field ambient constant temperature.

The continuity equation (1) can be satisfied automatically by introducing a stream function $\psi$ such that $u=\partial \psi / \partial y$ and $v=-\partial \psi / \partial x$. The momentum and energy equations are transformed by the similarity variables

$$
\begin{aligned}
& \eta=\left(\frac{U_{\infty}}{v x}\right)^{1 / 2} y, \\
& \psi=\left[v x U_{\infty}\right]^{1 / 2} f(\eta), \\
& \theta(\eta)=\frac{k\left(T-T_{\infty}\right)}{q_{w}}\left(\frac{U_{\infty}}{v x}\right)^{1 / 2}
\end{aligned}
$$

into the following nonlinear ordinary differential equations:

$$
\begin{gathered}
f^{\prime \prime \prime}+\frac{m+1}{2} f f^{\prime \prime}+m\left(1-f^{\prime 2}\right)+\lambda \theta=0, \\
\frac{1}{\operatorname{Pr}} \theta^{\prime \prime}+\frac{m+1}{2} f \theta^{\prime}-(2 m-1) f^{\prime} \theta=0 .
\end{gathered}
$$

The transformed boundary conditions are

$$
\begin{aligned}
& f(0)=0, \quad f^{\prime}(0)=\varepsilon, \quad \theta^{\prime}(0)=-1, \\
& f^{\prime}(\eta) \longrightarrow 1, \quad \theta(\eta) \longrightarrow 0 \quad \text { as } \eta \longrightarrow \infty,
\end{aligned}
$$


TABLE 1: Comparison of the values of $f^{\prime \prime}(0)$ with those of Wang [29] when $m=1$ and $\lambda=0$.

\begin{tabular}{lcc}
\hline$\varepsilon$ & Wang [29] & Present \\
\hline 5 & -10.26475 & -10.26475 \\
2 & -1.88731 & -1.88730 \\
1 & 0 & 0 \\
0.5 & 0.71330 & 0.71329 \\
0.2 & 1.05113 & 1.05113 \\
0.1 & 1.14656 & 1.14656 \\
0 & 1.232588 & 1.23259 \\
\hline
\end{tabular}

where $\varepsilon=a / b$. Here primes denote differentiation with respect to $\eta, \lambda=G r_{x} / \operatorname{Re}_{x}^{5 / 2}$ is the buoyancy or mixed convection parameter, $\operatorname{Pr}=\nu / \alpha$ is the Prandtl number, $G r_{x}=g \beta q_{w} x^{4} /\left(k v^{2}\right)$ is the local Grashof number, and $\operatorname{Re}_{x}=U_{\infty} x / v$ is the local Reynolds number. We note that $\lambda$ is a constant, with $\lambda>0$ corresponds to the assisting flow and $\lambda<0$ denotes the opposing flow whilst $\lambda=0$ is for forced convective flow. For the forced convection flow $(\lambda=0)$, the corresponding temperature problem possesses a larger similarity-solution domain than the mixed convection $(\lambda \neq 0)$ one. The reason is that in the forced convection case, the existence of similarity solutions does not require the restriction of the applied wall heat flux to the special form $q_{w}(x)=c x^{(5 m-3) / 2}$. Namely, in the forced convection case, the much weaker assumption $q_{w}(x)=c x^{n}$ suffices for the similarity reduction of the problem, where the flux exponent $n$ does not depend on the velocity exponent $m$ in any way.

The main physical quantities of interest are the values of $f^{\prime \prime}(0)$, being a measure of the skin friction, and the nondimensional wall temperature $\theta(0)$. Our main aim is to find how the values of $f^{\prime \prime}(0)$ and $\theta(0)$ vary in terms of the parameters $\lambda$ and $m$.

\section{Results and Discussion}

Equations (6) subject to the boundary conditions (7) are integrated numerically using a finite difference scheme known as the Keller box method [30]. Numerical results are presented for different physical parameters. To conserve space, we consider the Prandtl number as unity throughout this paper. The results presented here are comparable very well with those of Ramanchandran et al. [12]. For no buoyancy effects $\lambda=0$ and $m=1$, comparison of the values of $f^{\prime \prime}(0)$ was made with those of Wang [29] as presented Table 1, which shows a favourable agreement.

Figures 2 and 3 show the skin friction coefficient $f^{\prime \prime}(0)$ against buoyancy parameter $\lambda$ for some values of velocity exponent parameter $m$ when velocity ratio parameter is $\varepsilon=$ 0.5 and $\varepsilon=1$. Two branches of solutions are found. The solid lines are the upper branch solutions and the dash lines are the lower branch solutions. With increasing $m$, the range of $\lambda$ for which the solution exists increases. Also from both figures of the upper branch solutions, the skin friction is higher for the assisting flow $(\lambda>0)$ compared to the opposing flow $(\lambda<0)$. This implies that increasing the buoyancy parameter $\lambda$ increases the skin friction coefficient $f^{\prime \prime}(0)$ whilst for $\varepsilon=1$, the values of $f^{\prime \prime}(0)$ as shown in Figure 3 are positive for $\lambda>0$ and negatives for $\lambda<0$. Physically, this means that positive $f^{\prime \prime}(0)$ implies the fluid exerts a drag force on the sheet and negative implies the reverse. Similarly this also happens for $\varepsilon=0.5$ but at different values of $\lambda$.

As seen in Figures 2 and 3, there exists a critical value of velocity ratio $\lambda_{c}$ such that for $\lambda<\lambda_{c}$ there will be no solutions, for $\lambda_{c}<\lambda<0$ there will be dual solutions, and when $\lambda>0$, the solution is unique. Our numerical computations presented in Figure 2 show that for the velocity ratio $\varepsilon=0.5, \lambda_{c}=-8.331,-2.677$, and -0.7411 for $m=2,1$, and 0.5 , respectively. On the other hand, for the velocity ratio $\varepsilon=1$ shown in Figure $3, \lambda_{c}=-14.98,-4.764$, and -1.301 for $m=2$, 1 , and 0.5 , respectively. The dual solutions exhibit the normal forward flow behavior and also the reverse flow where $f^{\prime}(\eta)<$ 0 . From these two results, it seems that an increase in velocity ratio parameter $\varepsilon$ leads to an increase of the critical values of $\left|\lambda_{c}\right|$. This increases the dual solutions range of (6)-(7).

Figures 4 and 5 display the variations of the wall temperature $\theta(0)$ against the buoyancy parameter $\lambda$, for some values of $m$ when $\varepsilon=0.5$ and $\varepsilon=1$, respectively. Both figures clearly show that the wall temperature increases as $m$ increases for the upper branch solutions. For the lower branch solutions, the wall temperature becomes unbounded as $\lambda \rightarrow 0^{-}$.

The velocity and temperature profiles for $\varepsilon=0.5$ when $\lambda=-0.5$ are presented in Figures 6 and 7, respectively. Figure 6 shows that the velocity increases as $m$ increases for the upper branch solutions, while opposite trend is observed for the lower branch solutions. In Figure 7, for the upper branch solutions, it is seen that an increase in $m$ tends to decrease the temperature. Besides that, the temperature is higher for the lower branch solution than the upper branch solution at all points, near and away from the solid surface. It can be seen from Figures 6 and 7 that all profiles approach the far field boundary conditions (7) asymptotically, thus supporting the numerical results obtained. Finally, the typical streamlines for $m=1, \varepsilon=1$, and $\lambda=-2$ for both solution branches are shown in Figures 8 and 9.

\section{Conclusions}

The problem of mixed convection stagnation-point flow towards a nonlinearly stretching vertical sheet immersed in an incompressible viscous fluid was investigated numerically. The effects of the velocity exponent parameter $m$, buoyancy parameter $\lambda$, and velocity ratio parameter $\varepsilon$ on the fluid flow and heat transfer characteristics were discussed. It was found that for the assisting flow, the solution is unique, while dual solutions were found to exist for the opposing flow up to a certain critical value $\lambda_{c}$. Moreover, increasing the velocity exponent parameter $m$ is to increase the range of the buoyancy parameter $\lambda$ for which the solution exists.

\section{Nomenclature}

$a, b, c$ : Constants

$f: \quad$ Dimensionless stream function

$g$ : Acceleration due to gravity 


\author{
$G r_{x}$ : Local Grashof number \\ $k$ : Thermal conductivity \\ $m$ : Velocity exponent parameter \\ Pr: Prandtl number \\ $q_{w}$ : Surface heat flux \\ $\mathrm{Re}_{x}$ : Local Reynolds number \\ $T$ : $\quad$ Fluid temperature \\ $T_{\infty}$ : Ambient temperature \\ $u, v$ : Velocity components along the $x$ - and \\ $y$-directions, respectively \\ $U_{\infty}$ : Free stream velocity \\ $U_{w}$ : Stretching velocity \\ $x, y$ : Cartesian coordinates along the surface \\ and normal to it, respectively.
}

\section{Greek Letters}

$\alpha$ : Thermal diffusivity

$\beta$ : Thermal expansion coefficient

$\varepsilon$ : Velocity ratio parameter

$\eta$ : Similarity variable

$\theta$ : Dimensionless temperature

$\lambda$ : Buoyancy parameter

$v$ : Kinematic viscosity

$\rho$ : Fluid density

$\Psi$ : Stream function.

\section{Subscripts}

$w$ : Condition at the solid surface

$\infty$ : Condition far away from the solid surface.

\section{Superscript}

': Differentiation with respect to

\section{Acknowledgments}

The authors wish to thank the anonymous reviewers for their valuable comments and suggestions. The third author would like to acknowledge the financial supports received from the Universiti Kebangsaan Malaysia under the incentive grants UKM-GUP-2011-202 and DIP-2012-31.

\section{References}

[1] M. V. Karwe and Y. Jaluria, "Fluid flow and mixed convection transport from a moving plate in rolling and extrusion processes," Journal of Heat Transfer, vol. 110, no. 3, pp. 655-661, 1988.

[2] M. V. Karwe and Y. Jaluria, "Numerical simulation of thermal transport associated with a continuously moving flat sheet in materials processing," ASME Journal of Heat Transfer, vol. 113, no. 3, pp. 612-619, 1991.

[3] L. J. Crane, "Flow past a stretching plate," Journal of Applied Mathematics and Physics, vol. 21, no. 4, pp. 645-647, 1970.
[4] P. D. Weidman and Magyari, "Generalized Crane flow induced by continuous surfaces stretching with arbitrary velocities," Acta Mechanica, vol. 209, no. 3-4, pp. 353-362, 2010.

[5] P. D. Weidman and M. E. Ali, "Aligned and nonaligned radial stagnation flow on a stretching cylinder," European Journal of Mechanics B/Fluids, vol. 30, no. 1, pp. 120-128, 2011.

[6] C. H. Chen, "Laminar mixed convection adjacent to vertical, continuously stretching sheets," Heat and Mass Transfe, vol. 33, no. 5-6, pp. 471-476, 1998.

[7] M. Ali and F. Al-Yousef, "Laminar mixed convection boundary layers induced by a linearly stretching permeable surface," International Journal of Heat and Mass Transfer, vol. 45, no. 21, pp. 4241-4250, 2002.

[8] A. Ishak, R. Nazar, and I. Pop, "Mixed convection boundary layers in the stagnation-point flow toward a stretching vertical sheet," Meccanica, vol. 41, no. 5, pp. 509-518, 2006.

[9] A. Ishak, R. Nazar, and I. Pop, "Hydromagnetic flow and heat transfer adjacent to a stretching vertical sheet," Heat and Mass Transfer, vol. 44, no. 8, pp. 921-927, 2008.

[10] F. M. Ali, R. Nazar, N. M. Arifin, and I. Pop, "Effect of Hall current on MHD mixed convection boundary layer flow over a stretched vertical flat plate," Meccanica, vol. 46, no. 5, pp. 11031112, 2011.

[11] D. Pal, "Heat and mass transfer in stagnation-point flow towards a stretching surface in the presence of buoyancy force and thermal radiation," Meccanica, vol. 44, no. 2, pp. 145-158, 2009.

[12] N. Ramachandran, T. S. Chen, and B. F. Armaly, "Mixed convection in stagnation flows adjacent to vertical surfaces," ASME Journal of Heat Transfer, vol. 110, no. 2, pp. 373-377, 1988.

[13] M. Ayub, H. Zaman, M. Sajid, and T. Hayat, "Analytical solution of stagnation-point flow of a viscoelastic fluid towards a stretching surface," Communications in Nonlinear Science and Numerical Simulation, vol. 13, no. 9, pp. 1822-1835, 2008.

[14] N. Bachok, A. Ishak, and I. Pop, "On the stagnation-point flow towards a stretching sheet with homogeneous-heterogeneous reactions effects," Communications in Nonlinear Science and Numerical Simulation, vol. 16, no. 11, pp. 4296-4302, 2011.

[15] N. Bachok, A. Ishak, and I. Pop, "Boundary layer stagnationpoint flow and heat transfer over an exponentially stretching/shrinking sheet in a nanofluid," International Journal of Heat and Mass Transfer, vol. 55, pp. 8122-8128, 2012.

[16] N. Bachok, A. Ishak, and I. Pop, "Melting heat transfer in boundary layer stagnation-point flow towards a stretching/shrinking sheet," Physics Letters A, vol. 374, no. 40, pp. 4075-4079, 2010.

[17] K. Bhattacharyya, "Dual solutions in boundary layer stagnation-point flow and mass transfer with chemical reaction past a stretching/shrinking sheet," International Communications in Heat and Mass Transfer, vol. 38, no. 7, pp. 917-922, 2011.

[18] T. Hayat, Z. Abbas, and M. Sajid, "MHD stagnation-point flow of an upper-convected Maxwell fluid over a stretching surface," Chaos, Solitons and Fractals, vol. 39, no. 2, pp. 840-848, 2009.

[19] W. Ibrahim, B. Shankar, and M. M. Nandeppanavar, "MHD stagnation point flow and heat transfer due to nanofluid towards a stretching sheet," International Journal of Heat and Mass Transfer, vol. 56, pp. 1-9, 2013.

[20] A. Ishak, K. Jafar, R. Nazar, and I. Pop, "MHD stagnation point flow towards a stretching sheet," Physica A, vol. 388, no. 17, pp. 3377-3383, 2009. 
[21] F. Labropulu, D. Li, and I. Pop, "Non-orthogonal stagnationpoint flow towards a stretching surface in a non-Newtonian fluid with heat transfer," International Journal of Thermal Sciences, vol. 49, no. 6, pp. 1042-1050, 2010.

[22] G. C. Layek, S. Mukhopadhyay, and Sk. A. Samad, "Heat and mass transfer analysis for boundary layer stagnationpoint flow towards a heated porous stretching sheet with heat absorption/generation and suction/blowing," International Communications in Heat and Mass Transfer, vol. 34, no. 3, pp. 347-356, 2007.

[23] L. Y. Yian, N. Amin, and I. Pop, "Mixed convection flow near a non-orthogonal stagnation point towards a stretching vertical plate," International Journal of Heat and Mass Transfer, vol. 50, no. 23-24, pp. 4855-4863, 2007.

[24] T. R. Mahapatra, S. Dholey, and A. S. Gupta, "Oblique stagnation-point flow of an incompressible visco-elastic fluid towards a stretching surface," International Journal of NonLinear Mechanics, vol. 42, no. 3, pp. 484-499, 2007.

[25] J. Paullet and P. Weidman, "Analysis of stagnation point flow toward a stretching sheet," International Journal of Non-Linear Mechanics, vol. 42, no. 9, pp. 1084-1091, 2007.

[26] H. Rosali, A. Ishak, and I. Pop, "Stagnation point flow and heat transfer over a stretching/shrinking sheet in a porous medium," International Communications in Heat and Mass Transfer, vol. 38, no. 8, pp. 1029-1032, 2011.

[27] N. A. Yacob, A. Ishak, and I. Pop, "Melting heat transfer in boundary layer stagnation-point flow towards a stretching/shrinking sheet in a micropolar fluid," Computers and Fluids, vol. 47, no. 1, pp. 16-21, 2011.

[28] J. H. Merkin and T. Mahmood, "Mixed convection boundary layer similarity solutions: prescribed wall heat flux," Journal of Applied Mathematics and Physics, vol. 40, no. 1, pp. 51-68, 1989.

[29] C. Y. Wang, "Stagnation flow towards a shrinking sheet," International Journal of Non-Linear Mechanics, vol. 43, no. 5, pp. 377-382, 2008.

[30] H. B. Keller, "A new difference scheme for parabolic problems," in Numerical Solution of Partial-Differential Equations, J. Bramble, Ed., vol. 2, pp. 327-350, Academic Press, New York, NY, USA, 1970. 


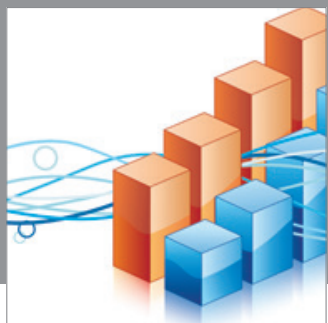

Advances in

Operations Research

mansans

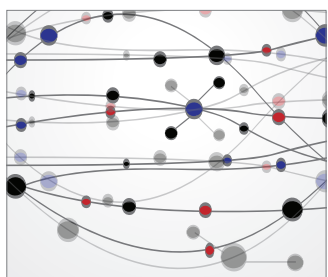

The Scientific World Journal
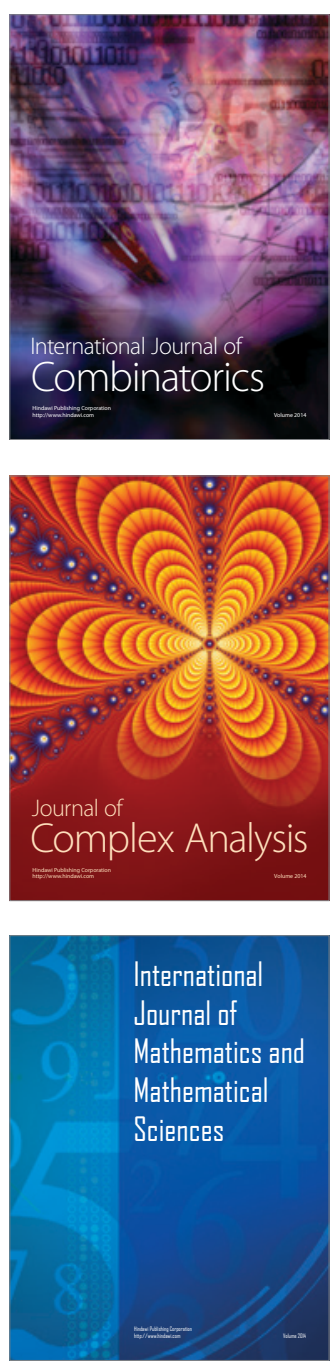
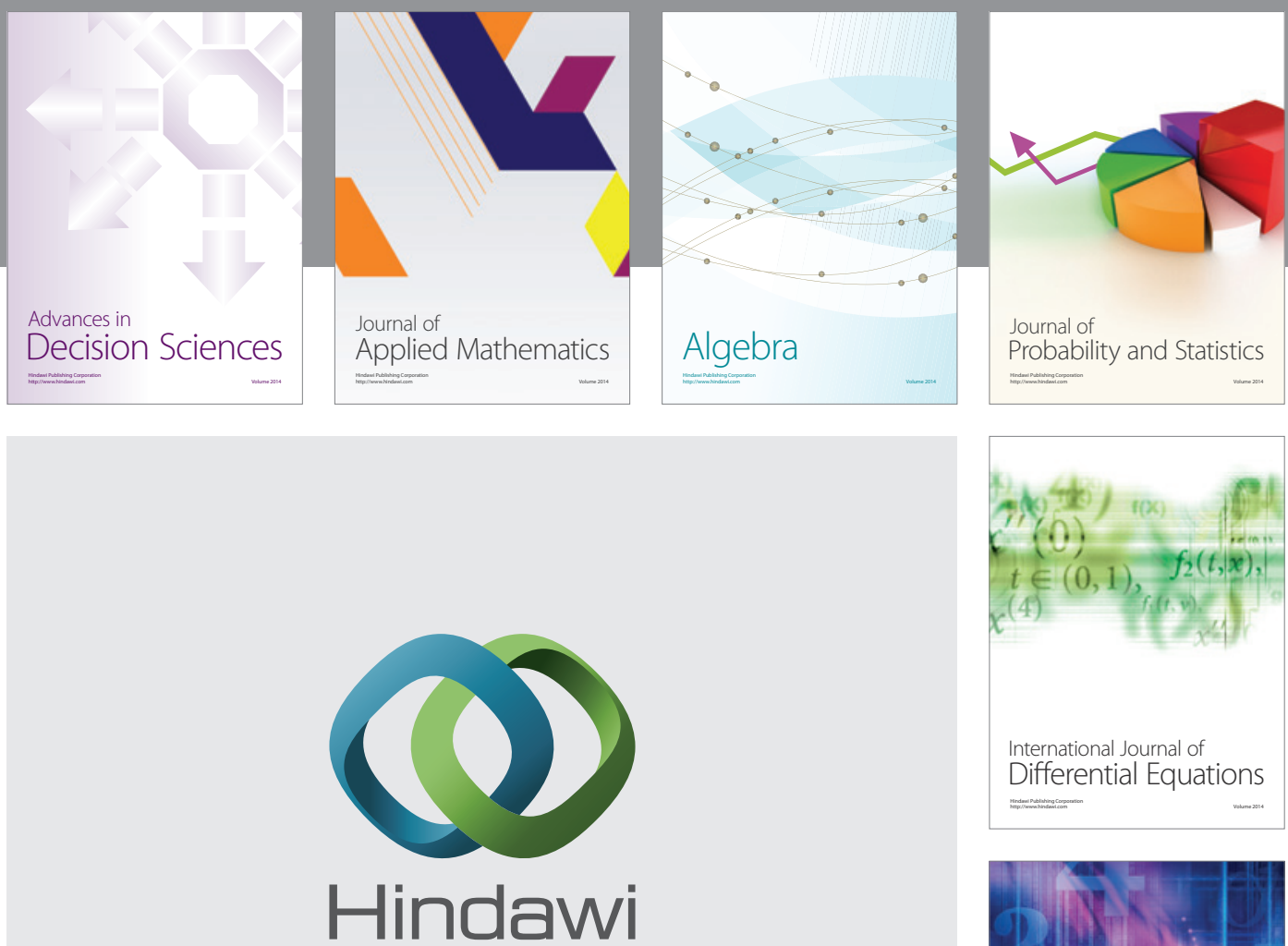

Submit your manuscripts at http://www.hindawi.com
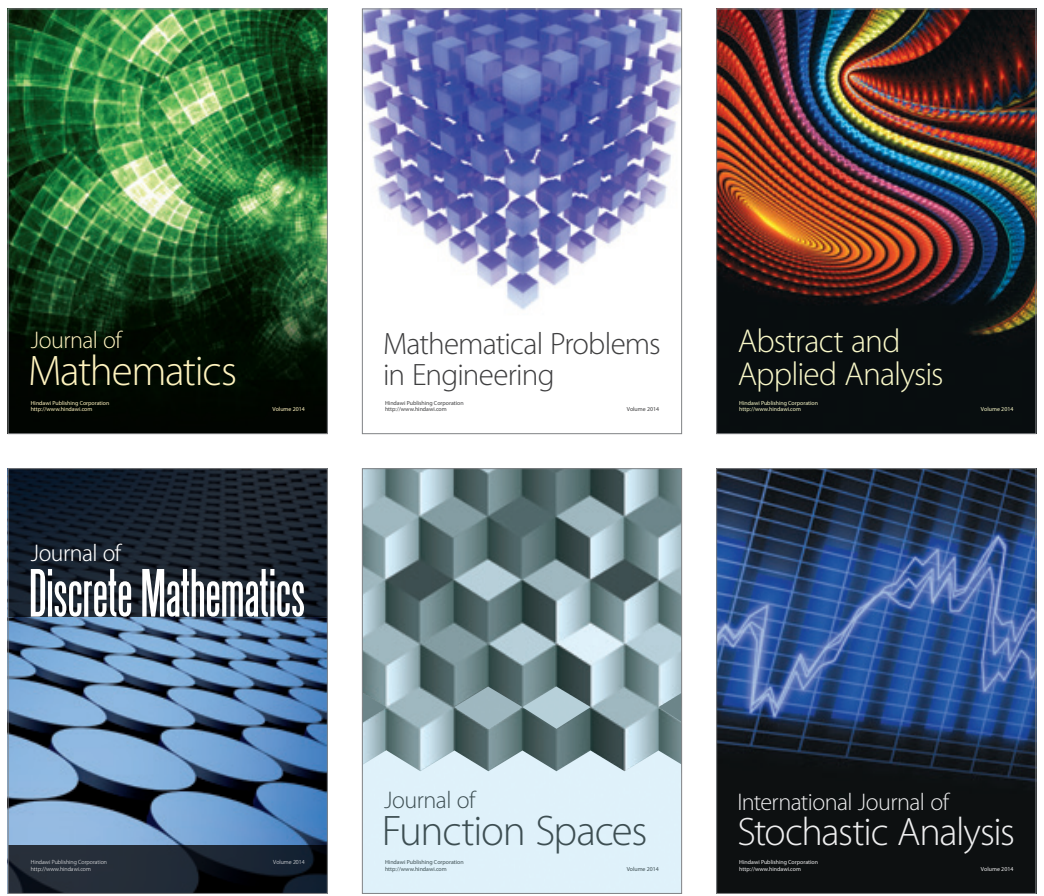

Journal of

Function Spaces

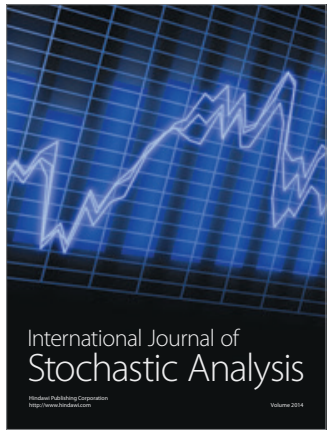

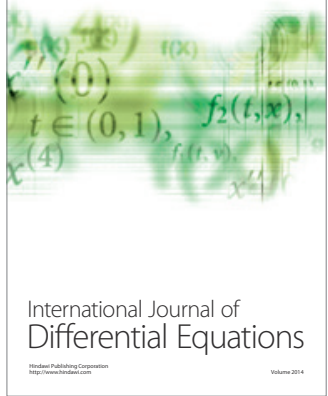
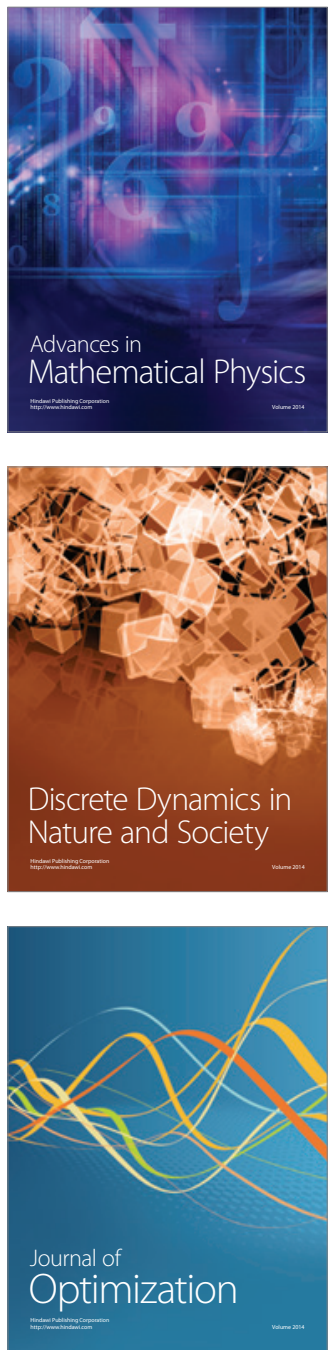